\title{
PROCESSO DE UNIFORMIZAÇÃO DO DIREITO INTERNACIONAL PRIVADO NAS AMÉRICAS: \\ Tratado de Lima de 1878, Tratados de Montevidéu de 1889 e 1940 e Código de Bustamante
}

\author{
PROCESS OF UNIFORMIZING PRIVATE LAW IN THE AMERICAS: LIMA TREATY \\ OF 1878, MONTEVIDEO TREATIES UNIFORMIZATION PROCESS OF PRIVATE \\ INTERNATIONAL LAW IN THE AMERICAS: \\ Lima Treaty of 1878, Montevideo Treaties of 1889 and 1940 and Customer Code
}

O presente artigo tem como objeto a verificação da contribuição americana ao processo de uniformização do Direito Internacional Privado a partir do estudo dos antecessores das Convenções Especializadas Interamericanas sobre Direito Internacional Privado - CIDIPs. Para tal fim, o artigo fará um recorte histórico, partindo das iniciativas de Simón Bolívar, com a conformação política regional do século XIX, descrevendo o envolvimento dos Estados Americanos na construção do Direito Privado no continente americano, traçando o contexto que permitiu o surgimento das Conferências Especializadas Interamericanas sobre Direito Internacional Privado e a influência desse histórico na elaboração das convenções americanas, destacando as características decisivas no desenvolvimento das codificações, bem como seus principais objetos de Direito Privado. Abordar-se-á o fenômeno da uniformização no Direito Americano, apresentando a recepção e a aplicação do Tratado de Lima de 1878, dos Tratados de Montevidéu de 1888/1889 e sua revisão em 1939/1940, bem como do Código de Bustamante, de 1928. Traçar-se-á um breve comparativo dos principais marcos dos citados Tratados e do Código de Bustamante, expondo as inovações para a integração regional, com foco na cooperação dos temas codificados ao processo de uniformização americana. A metodologia utilizada será a dedução, utilizando-se da investigação legislativa e doutrinária sobre o tema.

Palavras-chave: Direito Internacional Privado. Tratado de Lima de 1878. Tratados de Montevidéu. Código de Bustamante. Uniformização do Direito Privado.

\section{ABSTRACT}

The purpose of this article is to verify the American contribution to the process of standardizing Private International Law based on the study of the predecessors of the Inter-American Specialized Conventions on Private International Law - CIDIPs. To this end, the article will make a historical outline, starting from the initiatives of Simón Bolívar, with the regional political conformation of the 19th century, describing the involvement of American States in the construction of Private Law in the American continent, tracing the context that allowed the emergence of Inter-American Specialized Conferences on Private International Law and the influence of this history in the elaboration of American conventions, highlighting the decisive characteristics in the development of codifications, as well as their main objects of Private Law.

\footnotetext{
${ }^{1}$ Doutor em Direito (UFPE). Professor de Direito Internacional Privado na Faculdade de Direito do Recife (UFPE). ${ }^{2}$ Mestranda em Direito (UFPE).
} 
The phenomenon of uniformization in American Law will be addressed, presenting the reception and application of the 1878 Treaty of Lima, the 1888/1889 Montevideo Treaties and its revision in 1939/1940, as well as the Bustamante Code, of 1928. A brief comparison of the main milestones of the aforementioned Treaties and the Code of Bustamante will be drawn up, exposing innovations for regional integration, with a focus on the cooperation of the codified themes to the American uniformization proc.

Keywords: Private International Law. Lima Treaty of 1878. Treaties of Montevideo. Bustamante Code. Standardization of Private Law.

\section{INTRODUÇÃ̃O}

O Direito Americano, especificamente as iniciativas americanas de uniformização do Direito Internacional Privado, tem contribuído para o desenvolvimento da temática em âmbito global, sendo a proposta do presente estudo a verificação da carga jurídica indicativa do fomento continental ao desdobramento e alinhamento da estandardização do Direito Privado Americano. As primeiras tentativas remetem à idealização de confederação e união dos Estados Americanos, como foi planejado por Simón Bolívar no Congresso do Panamá de 1826, com a participação de GranColombia (Colômbia, Equador, Panamá e Venezuela de hoje), Peru, México e a Federação Centro-americana (Costa Rica, El Salvador, Guatemala, Honduras e Nicarágua).

A partir disso, tem-se uma série de tratativas regionais para estabelecer as bases de integração americana e uniformização do Direito, objetivando o desenvolvimento do continente e a garantia da independência daqueles que habitam entre o Oceano Atlântico e o Oceano Pacífico.

Percorrendo-se as iniciativas do século XIX, até os dias atuais, encontra-se, além do desenvolvimento da uniformização em âmbito global, a estruturação da padronização na América, com a elaboração de codificações que se tornaram o fundamento das CIDIPs, nas quais há a aprovação de convenções especializadas na esfera do Direito Internacional Privado.

Durante o marcado período histórico, viu-se a passagem de centralizadoras codificações para a escolha de elaboração de acordosem assuntos específicos, mas flexíveis, permitindo um rearranjo diante das múltiplas legislações internacionais e de cada Estado.

O presente estudo constatará a contribuição americana ao processo de uniformização do Direito Internacional Privado, traçando um contexto histórico com enfoque no Tratado de Lima de 1878, nos Tratados de Montevidéu de 1888/1889 e sua revisão em 1939/1940, bem como no Código de Bustamante de 1928, que são a base das atuais CIDIPs.

Quanto à metodologia, o estudo se utiliza da dedução, cujas informações são oriundas da pesquisa dogmática de artigos que trazem conteúdo relevante para o tema proposto e da investigação legislativa dos documentos citados.

\subsection{BREVE HISTÓRICO DA INICIATIVA DE UNIFORMIZAÇÃO AMERICANA}

A partir das crescentes conquistas do processo de globalização jurídica (THORNILL, 2017), com proeminência atual de temas internacionais como Arbitragem Comercial, Direito Comercial, Direitos Humanos e, ainda, os processos de importação e exportação (GARTH, 2009), verifica-se a padronização de matérias jurídicas como contribuição para a construção da aldeia global, de forma integrativa. No aspecto regional, constata-se o desenvolvimento da estandardização ao compreender o papel dos Estados americanos ao observar a gradativa evolução dos sucessos eventos históricos, políticos e jurídicos do Direito Internacional Privado.

Nas iniciativas de Uniformização do Direito Privado, no contexto continental americano, encontra-se variadas tratativas e documentos oficiais desde o século XIX até as décadas atuais. 


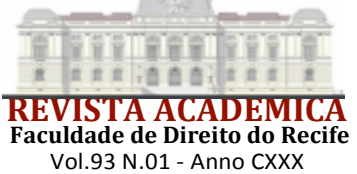

Entre as principais reuniões com a finalidade de unir o Direito Privado nas Américas, tem-se o Congresso do Panamá, promovido por Simón Bolívar, em 1826, destacado por Renato Alvares Gaspar e Mariana Romanello Jacob (2014, p. 690-691) como "um dos primeiros passos - mesmo ainda não embasados juridicamente - rumo à codificação do DIPr e aos tratados internacionais".

Após o citado Congresso, muitos convites, reuniões e legislações sucederam, tendo como destaque o Tratado de Confederação (REZA, 2010, p. 19-20), assinado em 8 de fevereiro de 1848, e os Congressos Americanos de Santiago, em 1856 e 1857, e de Lima, em 1864 e 1865 , dos quais resultaram o Tratado de Confederação Continental - ou Tratado de União Americana -, de 1856, bem como o Tratado de União e de Aliança Defensiva, o Tratado sobre Conservação da Paz entre os Estados de América Contratantes e o Tratado de Correios e Tratado de Comércio e Navegação (REZA, 2010, p. 23-24).

Entretanto, com a virada do século, em meados do século $\mathrm{XX}$, vê-se a gradual perda da relevância desses documentos. Como mencionado por Germán Reza, "o declive do movimento confederativo se viu estimulado pelo processo de diferenciação e a rivalidade dos Estados do subcontinente, assim como pelo desaparecimento da ameaça de reconquista, ao menos a espanhola" (REZA, 2010, p. 24) . $^{3}$

No corpo dos textos dos tratados e demais documentos firmados no século XIX, encontra-se o objetivo primário dos Estados participantes de criar, com união dos povos americanos, um mecanismo de defesa contra a dominação de outros povos e a favor do fortalecimento da independência americana. Entretanto, com a solidificação da independência dos Estados americanos, o objetivo principal das reuniões e do estabelecimento de tratados foi perdendo o significado. Sobre isso, Germán Reza menciona que "para alguns analistas, o aspecto defensivo das confederações as converteu em desnecessárias naquela época” (REZA, 2010, p. $24)^{4}$.

Entretanto, o objetivo político mudou e passou a centralizar nas produções jurídicas no contexto americano. Nesse intuito, tem-se, em 1875, o patrocínio peruano para a realização da Conferência diplomática realizada em 1877, em Lima, que resultou, em 1878, na assinatura do Tratado de Lima, considerado como um marco à tradição da Conferência Especializada Interamericana sobre Direito Internacional Privado (RODAS; MONACO, 2007, p. 101; GASPAR; JACOB, 2014, p. 691).

É perceptível a abertura política dos Estados americanos para definir como objetivo, ainda que de longo prazo, a concretização de iniciativas de Uniformização do Direito Privado. É o caso, por exemplo, do Relatório brasileiro do ano de 1876, apresentado à Assembleia Geral Legislativa na $1^{\text {a }}$ Sessão da $16^{\text {a }}$ Legislatura pelo Ministro das Relações Exteriores, João Maurício Wanderley, no qual se cita o convite peruano, feito ao Brasil, para participar do Congresso de Plenipotenciários Jurisconsultos, destinados a tornar uniformes as legislações dos Estados americanos 5 .

O Ministro Wanderley ressaltou a importância da uniformização não somente no contexto americano, mas em um contexto e com ambições globais. Foi nesse mesmo sentido a iniciativa italiana de Pasquale Stanislao Mancini, em 1881, ao enviar convites aos representantes de

\footnotetext{
3،El declive delmovimiento confederativo se vio estimulado por elproceso de diferenciación y larivalidad de los Estados del subcontinente, así como por ladesaparición de laamenaza de reconquista, al menos laespaño la."

4 "Para algunos analistas, el aspecto defensivo de las confederaciones las convirtió em in necesarias en aquella época."

“"O governo imperial reconhece a conveniencia e mesmo a necessidade de se tornarem uniformes as legislações nos pontos indicados; crê que isso é possível em certa extensão, mas pensa que só se obterá em futuro remoto, menos pela ação diplomatica do que pela scientifica, individual e collectiva, e que é preferível aguardar o re sultado dos trabalhos do instituto de direito internacional. Tambem entende que, como a materia não é de inte resse exclusivamente americano, antes conviria um congresso geral do que o exclusivamente americano que se propõe. Em todo caso nada se poderia fazer sem permissão legislativa.”(BRASIL, 1877, p. 20)
} 
diferentes Estados de diferentes regiões do mundo para participação em uma conferência diplomática para uniformização das regras de execução de sentença estrangeira (RODAS; MONACO, 2007, p. 101).

No continente americano, as tratativas de uniformização continuaram e, entre 1888 e 1889, foi realizado o Primeiro Congresso Internacional Sul-americano - chamado de Congresso de Montevidéu. Os trabalhos do citado Congresso resultaram na elaboração da primeira edição dos Tratados de Montevidéu (GASPAR; JACOB, 2014, p. 691-692). A segunda edição dos citados Tratados foi elaborada em resposta ao Código de Bustamante da Conferência Panamericana, elaborado em 1928. O Congresso de Montevidéu realizou a revisão dos Tratados de Montevidéu, entre os anos 1939 e 1940, fruto dos trabalhos do Segundo Congresso Internacional Sul-americano.

Em 1889, no ano que se publicava os Tratados de Montevidéu pelo Congresso Internacional Sul-americano reunido em Montevidéu, foi realizada a primeira das Conferências Pan-americanas na cidade de Washington, nos Estados Unidos (GASPAR e JACOB, 2014, p. 692). Entretanto, como explicado por Ana Maria Villela (1984, p. 7-8), a ocorrência de múltiplos congressos nesse período não evitou o surgimento de resistências quanto à ideia de uniformização legislativa, pressionando Estados como Argentina e Uruguai a afirmarem a superioridade das legislações internas ${ }^{6}$.

Contudo, ainda que as oposições dificultassem o desenvolvimento da matéria, as negociações continuaram. E, em 1906, no Rio de Janeiro, ocorreu a Terceira Conferência Internacional Americana, na qual foi criada a Junta Internacional de Jurisconsultos - atualmente chamada de Comissão Jurídica Interamericana, integrada posteriormente à Organização dos Estados Americanos (OEA) - que cuida da codificação do Direito Internacional Público e Privado, entre outros temas (OEA, 2020).

Até meados do século XX, é possível identificar que as codificações fizeram parte dos objetivos de muitas das reuniões dos Estados americanos, lidas como cruciais para a Uniformização do Direito Privado. E, como consolidação desse posicionamento americano, em 1928, ocorreu, em Havana, a Sexta Conferência Pan-americana, que culminou com a elaboração do Código de Bustamante (GASPAR; JACOB, 2014, p. 692), se tratando de uma legislação codificada de Direito Internacional Privado nas Américas que influenciaria a formulação dos trabalhos nas CIDIPs.

Como resposta às múltiplas fontes de elaboração de documentos jurídicos em matéria de Direito Privado nas Américas, em 1948, durante a Nona Conferência Pan-americana, em Bogotá, é firmada a Carta da Organização dos Estados Americanos (GASPAR; JACOB, 2014, p. 693). E, em 1975 (GASPAR; JACOB, 2014, p. 693), dá-se início à Primeira Conferência Especializada Interamericana sobre Direito Internacional Privado (CIDIP-I), que se estendem até os dias atuais.

Como comentado por Ruben Belandro ${ }^{7}$, até o surgimento das CIDIPs, a preferência americana era pela codificação das normas de Direito Internacional Privado. E, como ensina

\footnotetext{
6"Quanto ao Congresso de Montevidéu também houve reação dos participantes quanto à uniformização legislativa, o que obrigou os representantes da Argentina (Roque SaenzPeña) e do Uruguai (Gonzalo Ramirez) a desfazer o malentendido, deixando claro que não se desejava uniformizar legislações internas, mas sim cuidar da lei aplicável aos conflitos oriundos do concurso de jurisdições." (VILLELA, 1984, p. 7-8),

7 "La década de 1970 y la que hoyvivimos, marca elfin de lacodificaciónomnicomprensiva y lapulverización delaregulación de las relaciones jurídicas privadas extranacionales em una constelación de Convenciones particulares. [...] Como consecuencia de esta codificación gradual estamos presenciando unprocesoinflacionario de las normas de Derecho Internacional Privado antes nunca visto, que a diferencia de lainflación económica, no es un privilegio reservado a los países americanos, dado que se encuentra em todas partes Del mundo como un fenómeno de lacivilización moderna" (BELANDRO, 1989, p. 297). Tradução Livre: A década de 1970 e aquela em que vivemos hoje, marca o fim da codificação abrangente e a pulverização da regulação das relações jurídicas privadas estrangeiras em uma constelação de convenções particulares. [...] Como consequência dessa codificação gradativa, assistimos a um processo inflacionário das regras do Direito Internacional Privado nunca antes visto, que, ao
} 
Carolina Magalhães $\operatorname{Rech}^{8}$, a abertura dessas Conferências deu início à realização de reuniões especializadas, com a elaboração e aprovação de resoluções, convenções, leis modelos e protocolos adicionais em matéria previamente definida.

Em 1975, ocorria a Primeira Conferência Especializada Interamericana sobre Direito Internacional Privado no Panamá. O número de convenções firmada - o total de seis - e a presença dos representantes dos Estados americanos - com a participação de dezenove países foram expressivos, indicando que a idealização de conferências para uniformizar o Direito Internacional Privado no âmbito das Américas tinha recebido apoio dos Estados participantes.

Outro dado importante sobre a CIDIP-I é a diversidade dos dezenove países participantes, sendo dois do Norte - Estados Unidos da América e México -, sete da América Central - Costa Rica, El Salvador, Guatemala, Honduras, Nicarágua, Panamá, República Dominicana -, e dez países do Sul - Argentina, Bolívia, Brasil, Chile, Colômbia, Equador, Paraguai, Peru, Uruguai e Venezuela. Os Estados Sul-americanos estiveram presentes em número expressivo, o que reforça a disposição da América do Sul em estabelecer a uniformização no âmbito jurídico americano, com históricas iniciativas e participações nos Congressos dos séculos XIX e XX.

Nos anos seguintes foram realizadas sucessivas conferências, com aprovação de diferentes convenções e protocolos adicionais (AYALA; et al: 1998). A CIDIP-II ocorreu em 1979, em Montevidéu, com aprovação de sete convenções e um protocolo adicional. Em 1984, ocorreu a CIDIP-III, em La Paz, com elaboração de três convenções e um protocolo adicional. A CIDIP-IV, ocorreu em 1989, novamente em Montevidéu, aprovando três convenções. Em 1994, durante a CIDIP-V, por sua vez, ocorrida na Cidade do México, foram firmadas duas convenções.

Após a CIDIP-V, até a finalização do presente estudo, não há mais convenções aprovadas. Entretanto, houve a aprovação de resoluções e regulamento com foco no estabelecimento de modelos e normas em assuntos de interesse do continente americano. Nesse sentido, na CIDIPVI, em 2002, foram aprovadas algumas resoluções, dentre elas, as que estabeleceram uma Lei Modelo e um Documento Uniforme sobre Direito Internacional Privado ${ }^{9}$ E, na CIDIP-VII, encerrada em 2009, foi aprovado um Regulamento Modelo ${ }^{10}$.

contrário da inflação econômica, não é um privilégio reservado aos países americanos, uma vez que está em toda parte do mundo como um fenômeno da civilização moderna.

8 “As Conferências Interamericanas de Direito Internacional Privado são reuniões especializadas, por iniciativa da OEA, que discutem um determinado assunto colocado em pauta previamente, buscando promover a uniformização e harmonização do direito internacional privado. Ao final de cada CIDIP, são criadas Convenções Interamericanas de Direito Internacional Privado, de acordo com o que se discutiu na Conferência. Desta forma, a sigla CIDIP designa, simultaneamente, a Conferência e seus frutos, as Convenções." (RECH, 2008).

9“A Sexta Conferência Especializada Interamericana sobre Direito Internacional Privado (CIDIP-VI) foi convocada pela Assembleia Geral da Organização dos Estados Americanos, em seu Vigésimo Sexto Período Ordinário de Sessões, mediante a resolução AG/RES. 1393 (XXVI-O/96). [...] A sessão de encerramento teve lugar na sextafeira, 8 de fevereiro de 2002, às 17h00. O Presidente da Conferência, Sua Excelência o Embaixador Didier Opertti, Ministro das Relações Exteriores do Uruguai, convidou as delegações acreditadas pelos Estados membros para participarem da CIDIP-VI a assinarem a Ata Final. O Presidente da Conferência pronunciou em seguida algumas palavras, manifestando seu prazer pelo êxito da Conferência, que aprovou uma Lei Modelo e um Documento Uniforme sobre Direito Internacional Privado; resumiu o trabalho realizado pela Conferência e frisou a importância dos acordos concluídos. Terminada a sua alocução, declarou oficialmente encerrada a Sexta Conferência Especializada Interamericana sobre Direito Internacional Privado.” (OEA:2002)

10“"Mediante as resoluções AG/RES. 1923 (XXXIII-O/03) e AG/RES. 2033 (XXXIV-O/04), a Assembleia Geral da Organização dos Estados Americanos convocou a Sétima Conferência Especializada Interamericana sobre Direito Internacional Privado (CIDIP-VI) e instruiu o Conselho Permanente a realizar consultas com os Estados membros acerca de possíveis temas da agenda. [...] A sessão de encerramento foi realizada em 9 de outubro de 2009 às 18h00. O Presidente da Conferência, Rodrigo Labardini, convidou as delegações dos Estados-membros credenciadas a participar da CIDIP-VII para assinar a Ata Final. A Secretaria-Geral da OEA, representada pelo Dr. Dante Negro, Diretor do Departamento de Direito Internacional, pronunciou algumas palavras de encerramento e expressou satisfação com o êxito da Conferência, a qual aprovou o Regulamento Modelo para o Registro de que trata a Lei Modelo Interamericana sobre Garantias Mobiliárias. Finalmente, o Presidente da Conferência destacou o trabalho 
Ainda sem publicação de Ata de Abertura da Oitava Conferência Especializada Interamericana sobre Direito Internacional Privado até a finalização do presente estudo, o Departamento de Direito Internacional da Subsecretaria de Assuntos Jurídicos, ligado à OEA, discute os possíveis tópicos dos debates da CIDIP-VIII com um resumo das conquistas das reuniões anteriores ${ }^{11}$ que, somado às Atas Finais das CIDIPs (OEA, 2002-2009) e ao quadro sinóptico de Elixeno Ayala e outros (1998), tem-se uma compilação dos textos aprovados pelas CIDIPs.

\begin{tabular}{|c|c|}
\hline $\begin{array}{c}\text { CONFERÊNCIA } \\
\text { (AYALA; } \text { et al, 1998, tradução } \\
\text { livre) }\end{array}$ & DOCUMENTOS OFICIAIS \\
\hline CIDIP-I $^{12}$ & CONVENÇÕES: \\
\hline
\end{tabular}

realizado pela Conferência e a importância dos acordos alcançados. Após essas palavras, declarou oficialmente encerrada a Sétima Conferência Especializada Interamericana sobre Direito Internacional Privado, no que se refere ao tema II: Garantias mobiliárias: registros eletrônicos para a implementação da Lei Modelo Interamericana sobre Garantias Mobiliárias." (OEA, 2009).

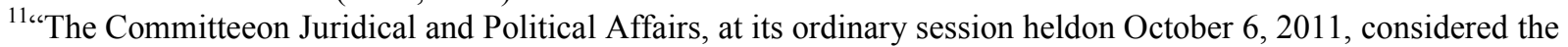
selection of new topics for a possible Eighth Specialized Inter-AmericanConferenceon Private International Law. To date, seven Specialized Inter-American Conferenceson Private International Law (CIDIP) have been held, resulting in the adoption of 27 Inter-American Instruments (including 20 Conventions, 3 Protocols, 1Model Law, 1 Model Regulation and 2 Uniform Documents). These instruments cover various topics designed to create an effective legal framework for legal cooperation between Inter-American States, to assist States in the progressive codification and y harmonization of their legal systems, and to foster justice and certainty in civil, family, commercialand procedural mattersacrossborders. The process for the developmentand codification of private international law via CIDIP began in Panama, Panama (CIDIP-I, 1975) and continued in Montevideo, Uruguay (CIDIP-II, 1979), La Paz, Bolivia (CIDIP-III, 1984), Montevideo, Uruguay(CIDIP-IV, 1989), Mexico City, Mexico (CIDIP-V, 1994), andat OAS Head quarters in Washington DC for CIDIP-VI in 2002 and again for CIDIP-VII in 2009 for the adoption of an instrument on secured transaction registries. Consideration of the second topic approved for CIDIP-VII on Consumer Protection is still pending. Currently, the Permanent Council's Committee en Juridical and Political Affairs requested the Department of International Law of the Secretariat for Legal Affairs to conduct preliminary inquiriesto determine potential topics and instruments for a possible CIDIP-VIII. The Department provided the present overview of the topic, previous proposals for inclusion of topics, and potential next steps at the ordinary session of the Committee held on October 6, 2011"(OEA: 2011). Tradução livre: A Comissão de Assuntos Jurídicos e Políticos, em sua sessão ordinária realizada em 6 de outubro de 2011, considerou a seleção de novos temas para uma possível Oitava Conferência Interamericana Especializada sobre Direito Internacional Privado. Até esta data, foram realizadas sete Conferências Interamericanas Especializadas de Direito Internacional Privado (CIDIP), resultando na adoção de 27 instrumentos interamericanos (incluindo 20 convenções, 3 protocolos, 1 lei modelo, 1 regulamento modelo e 2 documentos uniformes). Esses instrumentos abrangem diversos temas destinados a criar um quadro jurídico eficaz para a cooperação jurídica entre os Estados interamericanos, a auxiliar os Estados na codificação e harmonização progressiva de seus sistemas jurídicos e a promover a justiça e a segurança civil, familiar, comercial e processual. importa além das fronteiras. O processo de desenvolvimento e codificação do Direito Internacional Privado por meio da CIDIP teve início no Panamá, Panamá (CIDIP-I, 1975) e continuou em Montevidéu, Uruguai (CIDIP-II, 1979), La Paz, Bolívia (CIDIP-III, 1984), Montevidéu, Uruguai (CIDIP-IV, 1989), Cidade do México, México (CIDIP-V, 1994) e na Sede da OEA em Washington DC para a CIDIP-VI em 2002 e novamente para a CIDIP-VII em 2009 para a adoção de um instrumento em registros de transações seguras. Ainda está pendente a consideração do segundo tema aprovado para a CIDIP-VII sobre Defesa do Consumidor. Atualmente, a Comissão de Assuntos Jurídicos e Políticos do Conselho Permanente solicitou ao Departamento de Direito Internacional da Subsecretaria de Assuntos Jurídicos a realização de investigações preliminares para determinar os temas e instrumentos potenciais para uma possível CIDIP-VIII. O Departamento forneceu a presente visão geral do tema, propostas anteriores para inclusão de temas e possíveis próximos passos na sessão ordinária do Comitê realizada em 6 de outubro de 2011 .

12 “Convención Interamericana sobre de Arbitraje Comercial Internacional; ConvenciónInterarnericanasobre Conflictos de LeyesenMateria de Letras de Cambio, Pagarés y Facturas; Convención Interamericana sobre Conflictos de LeyesenMateria de Cheques; Convención Interamericana sobre Exhortos o Cartas Rogatorias; Convención Interamericana sobre Recepción de PruebasenelExtranjero; Convención Interamericana sobre Régimen Legal de Poderes para ser Utilizados enelExtranjero." 


\begin{tabular}{|c|c|}
\hline & $\begin{array}{l}\text { - Arbitragem Comercial Internacional; } \\
\text { - Conflitos de Leis Relativos a Letras de Câmbio, Notas } \\
\text { Promissórias e Faturas; } \\
\text { - Conflitos de Leis Referentes a Cheques } \\
\text { - Cartas Rogatórias, } \\
\text { - Recebimento de Provas no Exterior } \\
\text { - Regime Jurídico dos Poderes a Serem Usados no } \\
\text { Exterior. }\end{array}$ \\
\hline CIDIP-II $^{13}$ & $\begin{array}{l}\text { CONVENÇÕES: } \\
\text { - Conflitos de Leis Referentes a Cheques, } \\
\text { - Conflitos de Leis em Matéria de Sociedades } \\
\text { Comerciais, } \\
\text { - Cumprimento de Medidas Cautelares, } \\
\text { - Domicílio das Pessoas Naturais de Direito Internacional } \\
\text { Privado, } \\
\text { - Eficácia Extraterritorial de Sentenças Estrangeiras e } \\
\text { Sentenças Arbitrais, } \\
\text { - Normas Gerais de Direito Internacional Privado } \\
\text { - Provas e Informação sobre Direito Exterior. } \\
\text { PROTOCOLO: } \\
\text { - Protocolo Adicional à Convenção Interamericana sobre } \\
\text { Cartas Rogatórias }\end{array}$ \\
\hline CIDIP-III $^{14}$ & $\begin{array}{l}\text { CONVENÇÕES: } \\
\text { - Jurisdição na Esfera Internacional para a Eficácia } \\
\text { Extraterritorial das Sentenças Estrangeiras } \\
\text { - Conflitos de Leis Relativos à Adoção de Menores } \\
\text { - Personalidade e Capacidade das Pessoas Jurídicas de } \\
\text { Direito Internacional Privado. } \\
\text { PROTOCOLO: } \\
\text { Protocolo Adicional à Convenção Interamericana sobre } \\
\text { Recebimento de Provas no Exterior }\end{array}$ \\
\hline CIDIP-IV ${ }^{15}$ & $\begin{array}{l}\text { CONVENÇÕES: } \\
\text { - Contrato para o Transporte Internacional de } \\
\text { Mercadorias por Rodovias } \\
\text { - Obrigações de Manutenção } \\
\text { - Restituição Internacional de Menores }\end{array}$ \\
\hline
\end{tabular}

13 “Convención Interamericana sobre Conflictos de LeyesenMateria de Cheques; ConvenciónInteramericana sobreConflictos de LeyesenMateria de Sociedades Mercantiles; Convención Interamericana sobre Cumplimiento de Medidas Cautelares; Convención Interamericana sobre Domicilio de las Personas Físicas enel Derecho Internacional Privado; ConvenciónInterarnericana sobre Eficacia Extraterritorial de lasSentencias y Laudos ArbitralesExtranjeros; Convención Interamericana sobre Normas Generales de DerechoInternacional Privado; Convención Interamericana sobre Prueba e Información acerca delDerechoExtranjero; Protocolo Adicional a laConvención Interamericana sobre Exhortos o Cartas Rogatorias."

14“"Convención Interamericana sobre Competenciaenla Esfera Internacional para laEficacia Extraterritorial de las Sentencias Extranjeras; Convención Interamericana sobre Conflictos de LeyesenMateria de Adopción de Menores; Convención Interamericana sobre Personalidad y Capacidad de Personas Juridicas em elDerecho Internacional Privado; Protocolo Adicional a laConvenciónInterarnericana sobre Recepción de Pruebasen el Extranjero."

${ }_{15}^{15}$ “Convención Interamericana sobre Contrato de Transporte Internacional de Mercadería por Carretera; Convención In Peramericana sobre Obligaciones Alimentarias; Convención Enteramericana sobre Restitución Internacional de Menores." 


\begin{tabular}{|c|c|}
\hline CIDIP-V ${ }^{16}$ & $\begin{array}{l}\text { CONVENÇÕES: } \\
\text { - Direito Aplicável a Contratos Internacionais } \\
\text { - Tráfico Internacional de Menores }\end{array}$ \\
\hline CIDIP-VI & $\begin{array}{l}\text { RESOLUÇÕES: } \\
\text { - Lei Modelo Interamericana sobre Garantias Mobiliárias } \\
\text { (CIDIP-VI/RES. 5/02), } \\
\text { - Normas sobre Documentos e Assinaturas Eletrônicos } \\
\text { (CIDIP-VI/Res. n } 6 / 02) \text {, } \\
\text { - Lei Aplicável e Jurisdição Internacional Competente em } \\
\text { Matéria de Responsabilidade Civil Extracontratual } \\
\text { (CIDIP-VI/Res. No 7/02) } \\
\text { - Documentação Mercantil Uniforme para o Transporte } \\
\text { Internacional, com Referência Particular à Convenção } \\
\text { Interamericana sobre Contratos de Transporte } \\
\text { Internacional de Mercadorias por Estrada de Rodagem de } \\
\text { 1989 e a Possível Incorporação de um Protocolo } \\
\text { Adicional sobre Conhecimento de Embarque (CIDIP- } \\
\text { VI/Res.8/02) }\end{array}$ \\
\hline CIDIP-VII & $\begin{array}{l}\text { REGULAMENTO: } \\
\text { - Regulamento Modelo para o Registro de que trata a Lei } \\
\text { Modelo Interamericana sobre Garantias Mobiliárias, } \\
\text { anteriormente aprovada pela Resolução n } 6 / 02 \text {, da } \\
\text { CIDIP-VI. }\end{array}$ \\
\hline CIDIP-VIII & - \\
\hline
\end{tabular}

Entretanto, o modelo adotado pelas Conferências Especializadas Interamericana sobre Direito Internacional Privado de concretizar legislações quanto à matéria de forma gradual também apresenta problemas. Está presente, ainda, número considerável de normas que disciplinam a mesma matéria em diferentes documentos internacionais, coexistentes e válidos, gerando possíveis conflitos de leis na aplicação da norma adequada ao caso concreto. Problema apontado desde a década de $1980^{17}$.

$\mathrm{O}$ número de Estados participantes das Conferências Especializadas acenam para o aprofundamento de uma tradição americana em criar normas uniformes de Direito Internacional Privado. E a coexistência de múltiplas normas vigentes - existentes desde o século XIX - pode gerar conflitos e a solução estaria na criação de mecanismos de resolução de conflitos de leis, previstas nos textos das convenções especializadas (GASPAR; JACOB,2014, p. 701-704).

Ainda que múltiplas e coexistentes as normas em matéria de Direito Internacional Privado, é possível criar mecanismos de resolução de conflitos de leis nas CIDIPs. Como ensina

\footnotetext{
16“'Convención Interamericana sobre DerechoAplicable a los Contratos Internacionales; ConvenciónInteramericana sobre Trhfico Internacional de Menores."

${ }^{17}$ “Como un acto reflejo, elprofesional de derecho frente a un caso jusprivatista internacional podria pensar que el Uruguay por el solo hecho de ratificar estas nuevas Convenciones, quedaría desvinculado de los Tratados anteriormente ratificados respecto de lasmaterias específicas de que tratan. La realidad, sin embargo, no resultatansencilla como pudiera parecer y podríamosaventurarnos a sostener que enungran número de Convenciones de la CIDIP, sucede todo lo contrario." (BELANDRO, 1989, p. 297) Tradução Livre: Como ação reflexa, o profissional do direito diante de um caso jusprivatista internacional poderia pensar que o Uruguai, pelo simples fato de ratificar essas novas Convenções, estaria separado dos Tratados anteriormente ratificados quanto às matérias específicas de que tratam. A realidade, entretanto, não é tão simples quanto pode parecer e poderíamos nos aventurar a argumentar que em grande parte das Convenções da CIDIP ocorre o contrário.
} 
Renato Alvares Gaspar e Mariana Romanello Jacob ${ }^{18}$, a solução estaria no estabelecimento de mecanismos como as cláusulas de integração, permitindo a escolha da norma aplicável de forma mais coerente. Essas ferramentas contribuem para a eficácia do Direito Americano e o fortalecimento do regionalismo jurídico, partindo da modalidade associativa e, com pretensões futuras, de se estabelecer uma comunidade regional plena (BARZA, 2010, p. 118-126).

Ademais, os antecessores das Convenções Interamericanas de Direito Internacional Privado, a saber, o Tratado de Lima de 1878, os Tratados de Montevidéu 1889 e 1940 e o Código de Bustamante de 1928 - que fundamentaram as atuais CIDIPs - precedentemente colaboraram para a estruturação e o desenvolvimento da Uniformização do Direito Internacional Privado. A análise dos objetivos de tais documentos permitem a verificação da participação americana na construção jurídica que unifica os continentes.

\section{CODIFICAÇÕES AMERICANAS DO DIREITO INTERNACIONAL PRIVADO: TRATADO DE LIMA DE 1878, TRATADOS DE MONTEVIDÉU 1889 e 1940 E CÓDIGO DE BUSTAMANTE DE 1928}

\subsection{TRATADO DE LIMA DE 1878}

A verificação da contribuição da América para a uniformização jurídica em âmbito global permeia pela análise do Tratado de Lima de 1878. Sendo antecessor das Conferências Especializadas Interamericana sobre Direito Internacional Privado, o Tratado para Estabelecer Regras Uniformes em Matéria de Direito Internacional Privado 1877 foi assinado, em Lima, no dia 9 de novembro de 1878 e é recorrentemente citado como documento histórico de marco significativo na Uniformização do Direito Privado no âmbito americano.

Também conhecido como Tratado de Lima de 1878, este O Tratado de 1878 foi resultado dos trabalhos desenvolvidos no Congresso de Plenipotenciários Jurisconsultos reunidos em Lima por iniciativa do governo peruano. Foram sete Estados participantes, são eles: Peru, Argentina, Chile, Bolívia, Equador, Venezuela e Costa Rica. Do preâmbulo e do primeiro artigo do Tratado $^{19}$, é possível extrair que os Estados participantes entenderam como uma necessidade a uniformização da legislação nas Américas, sobretudo em matéria de Direito Internacional Privado, expressamente prevista no citado Tratado.

Conforme Ana Maria Villela ${ }^{20}$ ensina, o Tratado de Lima de 1878 é composto de sessenta artigos, dispondo sobre temas centrais de Direito Internacional Privado. O Tratado de Lima de

\footnotetext{
18، As cláusulas de integração são também relevantes por não engessarem os Estados aos tratados que ratificam. Embora indiquem - mormente às específicas - uma preferência e, portanto, um certo limite à opção por outro instrumento, as cláusulas não impedem ou restringem a aplicação deste de forma absoluta, permitindo que regras mais benéficas, expeditas, de caráter regional etc. sejam adotadas.” (GASPAR; JACOB, 2014, p. 713)

19“La República delPerú, la Argentina, la de Chile, la de Bolívia, ladelEcuador, la de los Estados Unidos de Venezuela y la de Costa-Rica, reconociendolanecesidad de uniformar, em cuantoseaposible, lalegislación delos Estados Americanos, decidieron, por iniciativa delGobiernodelPerú reunir en Lima unCongreso de Plenipotenciarios Jurisconsultos [...] Quienes, prévia exhibición de sus respectivos plenos poderes, que halla ron em debida forma, han discutido en una serie de conferencias laprimera parte del programa acordado, rela tivo al Derecho Internacional Privado; y hanconvenidoen que lasNaciones por ellos representadas, adoptarán comoleylasdisposicionescontenidasenlos títulos siguientes [...].” (OEA, 1938)Tradução Livre: A Repúbli ca do Peru, Argentina, Chile, Bolívia, Equador, Estados Unidos da Venezuela e Costa Rica, reconhecendo a necessidade de uniformizar, na medida do possível, a legislação dos Estados Americanos, decidiram, por inici ativa do Governo do Peru, convocar em Lima um Congresso de Membros Plenipotenciários Jurisconsultos [...] Que, depois de mostrarem seus respectivos plenos poderes, que acharam ser na devida forma, discutiram em uma série de conferências a primeira parte do programa acordado, relativa ao Direito Internacional Privado; e concordaram que as Nações por eles representadas adotem como lei as disposições contidas nos seguintes títulos $[\ldots]$

20 "Relembremos, primeiramente, o Tratado de Lima que, composto de 60 artigos, pretendia estabelecer regras uniformes em matéria de direito internacional privado, legislando sobre o estado e a capacidade jurídica das
} 
1878 foi dividido em oito títulos, conforme quadro abaixo, abordando questões como estado e capacidade jurídica, jurisdição e execução de sentença. Nos dizeres de Renato Alvares Gaspar e Mariana Romanello Jacob (2014, p. 691), “[o] Tratado de Lima (de 1878), estabeleceu regras uniformes de DIPr e disciplinou questões específicas da matéria".

\begin{tabular}{|c|c|}
\hline TÍTULOS & TEMAS (OEA, 1938) \\
\hline PRIMEIRO & $\begin{array}{l}\text { Da lei que rege o estado e a capacidade jurídica das pessoas, os bens } \\
\text { situados na República e os contratos celebrados em país estrangeiro }\end{array}$ \\
\hline SEGUNDO & $\begin{array}{l}\text { Dos matrimônios celebrados em país estrangeiro e dos celebrados por } \\
\text { estrangeiros na República }{ }^{22}\end{array}$ \\
\hline TERCEIRO & Da sucessão ${ }^{23}$ \\
\hline QUARTO & $\begin{array}{l}\text { Da competência dos Tribunais nacionais sobre atos jurídicos realizados } \\
\text { fora da República e sobre os celebrados por estrangeiros que não residem } \\
\text { nela }^{24}\end{array}$ \\
\hline QUINTO & $\begin{array}{l}\text { Da jurisdição nacional sobre delitos cometidos em país estrangeiro e sobre } \\
\text { os da falsificação em juízo de outros Estados (OEA, 1938) }\end{array}$ \\
\hline SEXTO & Da execução das sentenças e outros atos jurisdicionais ${ }^{26}$ \\
\hline SÉTIMO & Das legalizações $^{27}$ \\
\hline OITAVO & Disposições comum aos títulos precedentes ${ }^{28}$ \\
\hline
\end{tabular}

O Tratado de Lima de 1878codificou os temas de Direito Internacional Privado do contexto americano, o que se repetiria nos próximos documentos jurídicos do continente. Entretanto, a tentativa de uniformizar temas com diferentes abordagens jurídicas, como o instituto da nacionalidade, foi um empecilho para a adoção do Tratado de Lima de 1878 nos diferentes países americanos (PARRA-ARANGUREN, 1996, p. 72-81). Mas esta não foi a última tentativa de codificação americana, sendo seguido pelos Tratados de Montevidéu e pelo Código de Bustamante.

Destacando-se como o primeiro tratado no mundo a cuidar da matéria de Direito Internacional Privado, a América demonstrou não somente sua contribuição com a padronização global do tema, mas seu pioneirismo (VIZCARRA, 2012, p. 1-2). O Tratado para Estabelecer Regras Uniformes em Matéria de Direito Internacional Privado 1877 confirma o protagonismo do continente americano no estabelecimento das bases da Uniformização do Direito Internacional Privado, que se confirma, ainda, ao analisar-se a elaboração dos Tratados de Montevidéu 1889 e 1940 e do Código de Bustamante 1928.

pessoas, os bens e os contratos, o casamento, a sucessão, a competência dos tribunais nacionais, a jurisdição nacional sobre delitos cometidos no exterior, execução de sentenças e outros atos jurisdicionais, bem como legalizações." (VILLELA, 1984, p. 12)

21 "De laley que rigeel estado y lacapacidad jurídica de las personas, losbienes situados enla República y los contratos celebrados en país extranjero".

22 "De losmatrimonios celebrados en país extranjero y de los celebrados por extranjerosenla República".

${ }^{23}$ "De lasucesión".

24،"De lacompetencia de losTribunalesnacionales sobre actos jurídicos realizados fuera de la República y sobre los celebrados por extranjeros que no residenenella".

${ }^{25}$ "De lajurisdicción nacional sobre delitos cometidos en país extranjero y sobre los de lafalsificación em juicio deotros Estados".

26 "De laejecución de las sentencias y otros actos jurisdiccionales".

27 "De laslegalizaciones".

28 "Disposicionescomunes á los títulos precedentes". 


\subsection{TRATADOS DE MONTEVIDÉU 1889 e 1940}

Os Tratados de Montevidéu, assinados em 1889, apresentavam uma tendência universalista (PARRA-ARANGUREN, 1996, p. 90-91). Nesse sentido, tais documentos acompanhando a ideia vanguardista do Tratado de Lima de 1878 - não restringiram seu campo de aplicação. Assim, a elaboração dos textos oficias comprova a participação do continente americano na construção da Uniformização do Direito Internacional Privado em âmbito global.

Com tal característica, os Tratados de Montevidéu de 1889 foram o resultado dos trabalhos do Primeiro Congresso Internacional Sul-americano, etapa que demonstra maior amadurecimento no processo de uniformizaçãoe que tem como resultado a produção de normas que demonstravam organização e clareza nos propósitos. Os Tratados de Montevidéu de 1889 foram divididos em sete temas, nas áreas de civil e penal, entre outros mais específicos, além de um convênio sobre o exercício de profissionais liberais e um protocolo adicional ${ }^{29}$.

O Protocolo Adicional aos Tratados, por sua vez, demonstrou a intenção dos países congressistas de desenvolver a harmonização das leis vigentes de forma a aplicar, pelo juiz nacional, a lei de outro Estado Contratante, independentemente de serem nacionais ou estrangeiras as pessoas da relação jurídica.

Participaram das reuniões que resultaram nos Tratados de Montevidéu de 1889 representantes de sete países sul-americanos - Uruguai, Brasil, Bolívia, Argentina, Chile, Peru, Paraguai (ARGENTINA, 1894) (AYALA;et al, 1998). E, Eembora tentassem solucionar os problemas de divergência em matéria de Direito Internacional Privado e alcançar amplamente as adesões dos Estados americanos, os Tratados de Montevidéu de 1889 não obtiveram um número significativo de incorporações (GASPAR; JACOB, 2014, p. 691-692).

Ausentes a Costa Rica, a Venezuela e o Equador, as reuniões dos Tratados de Montevidéu de 1889 não obtiveram diferença quantitativa das reuniões do Tratado de Lima de 1878, contando com a participação do Brasil, do Uruguai e do Paraguai - que não estiveram nas reuniões do citado Tratado de Lima -, além de Peru, Argentina, Chile e Bolívia. Em resposta a essa baixa adesão, os Tratados de Montevidéu foram revisados entre os anos 1939 e 1940, durante o Segundo Congresso Internacional Sul-americano (Congresso de Montevidéu), trazendo algumas mudanças pontuais.

Participaram das reuniões que resultaram na Revisão de 1940 os representantes de oito países sul-americanos - Uruguai, Brasil, Bolívia, Colômbia, Argentina, Chile, Peru, Paraguai (AYALA;et al: 1998), não conquistando a participação da Costa Rica, da Venezuela e do Equador, ou de outro Estado americano, salvo a Colômbia.

O novo documento foi dividido em sete temas, além de um convênio e um protocolo adicional $^{30}$. Sem grandes inovações, essa revisão se deu em resposta à elaboração do Código de

\footnotetext{
${ }^{29}$ Art. $1^{\circ}$ da Lei argentina $n^{\circ} 3192$, de 6 de dezembro de 1894:Apruébanselos tratados de derecho civil, comer cial, penal, procesal, propiedadliteraria y artística, marcas de fábrica y de comercio y patentes de invención, el convenio referente al ejercicio de profesionesliberales y el Protocolo Adicional, sancionados por elCongreso Sudamericano de Derecho Internacional Privado que se reunióen Montevideo elveinticinco de agosto de mil ochocientosochenta y ocho y que suscribieronlosplenipotenciarios de la República. (ARGENTINA, 1894) Tradução Livre: Art. $1^{\circ}$ - Aprovar os tratados de direito civil, comercial, penal, processual, propriedade literá ria e artística, marcas de fábrica e de comércio e patentes de invenção, o convênio referente ao exercício das profissões liberais e o Protocolo Adicional, sancionado pelo Congresso Sul-Americano de Direito Internacio nal Privado que se reuniu em Montevidéu em vinte e cinco de agosto de mil oitocentos e oitenta e oito e que foi assinado pelos plenipotenciários da República.

30، Apruébenselos Tratados sobre Asilo y Refugio Políticos y Propiedad Intelectual y laConvención sobre Ejer cicios de ProfesionesLiberales, suscritos a 4 de Agosto de 1939, enlaReunión de Jurisconsultos de Montevi deo por losPlenipotenciarios de la República doctores Don Juis de Gásperi, Don Luís A. Argaña y Don Raúl Sapena Pastor; y los Tratados sobre Derecho Civil Internacional; DerechoProcesal Internacional; Derechode Navegación Comercial Internacional; Derecho Comercial Terrestre Internacional y el Protocolo Adicional
} 
Bustamante de 1928, que poderia impedir a ampliação das adesões dos Estados americanos aos Tratados de Montevidéu.

\begin{tabular}{|c|c|c|}
\hline TRATADOS & $\begin{array}{l}\text { TRATADO DE 1888-1889 } \\
\text { (ARGENTINA, 1894) }\end{array}$ & $\begin{array}{l}\text { TRATADO DE 1939-1940 } \\
\text { (PARAGUAI, 1955; 1960) }\end{array}$ \\
\hline \multirow{6}{*}{$\begin{array}{l}\text { DOCUMENTOS } \\
\text { SIMILARES }\end{array}$} & $\begin{array}{l}\text { Tratado de Direito Processual } \\
\text { Internacional } 1^{31}\left(1^{\circ}\right)\end{array}$ & $\begin{array}{c}\text { Tratado de Direito Processual } \\
\text { Internacional }{ }^{31}\left(8^{\circ}\right)\end{array}$ \\
\hline & $\begin{array}{l}\text { Tratado sobre Direito Penal } \\
\text { Internacional }^{32}\left(5^{\circ}\right)\end{array}$ & $\begin{array}{l}\text { Tratado sobre Direito Penal } \\
\text { Internacional }{ }^{32}\left(7^{\circ}\right)\end{array}$ \\
\hline & $\begin{array}{l}\text { Convenção sobre o Exercício de } \\
\text { Profissões Liberais }{ }^{33}\left(6^{\circ}\right)\end{array}$ & $\begin{array}{l}\text { Convenção sobre o Exercício de } \\
\text { Profissões Liberais }{ }^{33}\left(1^{\circ}\right)\end{array}$ \\
\hline & $\begin{array}{l}\text { Tratado de Direito Civil } \\
\text { Internacional }^{34}\left(7^{\circ}\right)\end{array}$ & $\begin{array}{l}\text { Tratado de Direito Civil } \\
\text { Internacional }^{34}\left(4^{\circ}\right)\end{array}$ \\
\hline & $\begin{array}{l}\text { Tratado de Direito Comercial } \\
\text { Terrestre Internacional }{ }^{35}\left(8^{\circ}\right)\end{array}$ & $\begin{array}{l}\text { Tratado de Direito Comercial } \\
\text { Terrestre Internacional }{ }^{35}\left(5^{\circ}\right)\end{array}$ \\
\hline & $\begin{array}{c}\text { Protocolo Adicional aos Tratados } \\
\text { de Direito Internacional } \\
\text { Privado }^{36}\left(9^{\circ}\right)\end{array}$ & $\begin{array}{c}\text { Protocolo Adicional aos Tratados } \\
\text { de Direito Internacional } \\
\text { Privado }^{36}\left(9^{\circ}\right)\end{array}$ \\
\hline SUBSTITUIÇÃO & $\begin{array}{c}\text { Tratado sobre Propriedade Literária } \\
\text { e Artística }{ }^{37}\left(2^{\circ}\right)\end{array}$ & $\begin{array}{c}\text { Tratado sobre Propriedade } \\
\text { Intelectual }{ }^{40}\left(3^{\circ}\right)\end{array}$ \\
\hline
\end{tabular}

suscritos a 19 de marzo de 1940 enlamismareunión de Jurisconsultos por losPlenipotenciarios de laRepúbli cadoctores Don RaúlSapena Pastor y Don Emilio SaguierAceval.” (PARAGUAI, 1955) “Apruébase y ratifi caseel Tratado de Derecho Penal Internacional, suscritoen Montevideo el 19 de marzo de 1940.” (PARA GUAI, 1960) Tradução Livre: “Os Tratados sobre Asilo Político e Refugiado e Propriedade Intelectual e a Convenção sobre o Exercício das Profissões Liberais, assinada em 4 de agosto de 1939, na Reunião de Juris consultos de Montevidéu pelos Plenipotenciários da República médicos Don Juis de Gásperi, Don Luís A. Argaña e Don RaúlSapena Pastor; e os Tratados de Direito Civil Internacional; Direito Processual Internacio nal; Direito Internacional da Navegação Comercial; O Direito Internacional do Comércio Territorial e o Proto colo Adicional assinados em 19 de março de 1940 na mesma Reunião de Jurisconsultos dos Plenipotenciários da República, Dr. RaúlSapena Pastor e Sr. Emilio SaguierAceval.” (PARAGUAI, 1955) “É aprovado e ratifi cado o Tratado de Direito

Penal Internacional, assinado em Montevidéu em 19 de março de 1940”. (PARAGUAI, 1960).

31، Tratado de DerechoProcesal Internacional".

32،"Tratado sobre Derecho Penal Internacional".

33، "Convención sobre elEjercicio de ProfesionesLiberales".

34 "Tratado de Derecho Civil Internacional".

35 "Tratado de Derecho Comercial Terrestre Internacional".

36"Protocolo Adicional a los Tratados de Derecho Internacional Privado".

37،"Tratado sobre PropiedadLiteraria y Artistica”. 


\begin{tabular}{|c|c|c|}
\hline & $\begin{array}{l}\text { Tratado sobre Marcas de Comércio } \\
\text { e de Fábrica }{ }^{38}\left(3^{\circ}\right) \\
\text { Tratado sobre Patentes de Invenção } \\
\qquad\left(4^{\circ}\right)^{39}\end{array}$ & \\
\hline & & $\begin{array}{l}\text { Tratado sobre Asilo e Refúgio } \\
\text { Políticos }{ }^{41}\left(2^{\circ}\right)\end{array}$ \\
\hline NOVOS & - & $\begin{array}{l}\text { Tratado de Direito de Navegação } \\
\text { Comercial Internacional }{ }^{42}\left(6^{\circ}\right)\end{array}$ \\
\hline
\end{tabular}

Nesse contexto, com o fim de organizar as múltiplas codificações americanas, foi firmada uma Carta e institucionalizada a Organização dos Estados Americanos - OEA (GASPAR; JACOB, 2014, p. 692-693). Então, viu-se uma mudança na abordagem do Direito Internacional Privado nas Américas e, em vez de codificações, passou-se a desenvolver elaborações graduais e especializadas das matérias internacionais, sobretudo com a abertura das Conferências Especializadas Interamericanas sobre Direito Internacional Privado, geridas pela OEA.

As diferentes abordagens do Direito Internacional Privado pelo continente americano, por codificações ou por convenções especializadas, demonstram o esforço em produzir conteúdo comum aos povos da América, ainda que a aplicabilidade no Direito interno sofresse, ao longo do século XIX e XX, alguns obstáculos em virtude dos interesses nacionais. A união em termos jurídicos foi tema das reuniões com representantes de todo o continente e os debates produziram material que se tornou fonte da estandardização nos níveis regionais e na esfera global.

\subsection{CÓDIGO DE BUSTAMANTE DE 1928}

A efetividade das codificações, com a adesão em massa dos Estados Americanos, sinalizaria o nível de desenvolvimento do processo de Uniformização do Direito Americano. Constata-se, assim, a dinamicidade entre a padronização jurídica e os avanços científicos que romperam as fronteiras nacionais, a partir da análise das características do Código de Bustamante de 1928 e da condução dos trabalhos sobre o documento.

Com a presença de vinte e um Estados americanos, no dia 21 de fevereiro de 1928, na cidade de Havana, em Cuba, durante a Sexta Conferência Internacional Americana/Panamericana, o Código de Direito Internacional Privado, conhecido como Código de Bustamante, foi ratificado por quinze dos Estados presentes. Pela expressiva participação dos representantes das Américas, o Código de Bustamante se tornou uma referência para as atuais convenções elaboradas pelas Conferências Especializadas Interamericanas sobre Direito Internacional Privado, conhecidas como CIDIPs.

Nos termos preliminares, o Código de Bustamante registra a participação de dez Estados sul-americanos - Peru, Uruguai, Equador, Bolívia, Venezuela, Colômbia, Chile, Brasil, Argentina e Paraguai -, dez da América Central - Panamá, El Salvador, Guatemala, Nicarágua, Honduras, Costa Rica, Haiti, República Dominicana e Cuba - e dois dos três Estados norte-americanos México e Estados Unidos da América ${ }^{43}$.

\footnotetext{
40،"Tratado sobre Propiedad Intelectual".

38“"Tratado sobre Marcas de Comercio y de Fábrica".

39"Tratado sobre Patentes de Invención".

41،"Tratado sobre Asilo y Refugio Políticos".

42،"Tratado de Derecho de Navegación Comercial Internacional".

43،"Los Presidentes de las Repúblicas de Perú, de Uruguay, de Panamá; de Ecuador, de México, de El Salvador, de Guatemala, daseNicaragua, de Bolivia, de Venezuela, de Colombia, de Honduras, de Costa Rica, de Chi
} 
O Código Bustamante de 1928 é uma norma abrangente que cuida de tratar de diferentes temáticas jurídicas no campo internacional, dividindo seu conteúdo em um Título Preliminar com as regras gerais - e quatro livros, com os seguintes assuntos: Direito Civil Internacional, Direito Mercantil Internacional, Direito Penal Internacional, Direito Processual Internacional (AYALA; et al, 1998, p. 713-808).

Entretanto, o Código de Bustamante não era, em seu tempo, a única legislação de Direito Internacional Privado elaborada nas Américas, pois o Tratado de Montevidéu havia sido assinado em 1889 e em vias de revisão - que ocorreria em 1940. Como citado anteriormente, a existência de múltiplas normas criou a necessidade de encarregar a um organismo internacional a administração das negociações futuras sobre a matéria. A Organização dos Estados Americanos foi designada a tarefa de realizar revisões e reuniões que dissessem respeito ao tema de Direito Internacional Privado (GASPAR; JACOB, 2014, p. 692-693).

Até o surgimento das CIDIPs, a preferência americana era pela codificação do tema jurídico. Mas a abertura das Conferências Especializadas deu início à realização de reuniões objetivas, elaborando-se mecanismos para os conflitos porventura existentes devido à multiplicidade de normas covigentesaplicáveis no âmbito americano (BELANDRO, 1989, p. 297) (RECH, 2008).

Por outro lado, ainda que, posteriormente, tenha surgido a predileção por documentos específicos, em detrimento das codificações - nas reuniões e na produção das CIDIPs -, o Código de Bustamante foi um marco para a uniformização do Direito Internacional Privado e seu estudo permite uma compreensão mais precisa da construção do Direito Internacional Privado na América.

\section{CONCLUSÃO}

A partir das análises iniciadas por este artigo, é possível constatar o aporte da América para o desenvolvimento da Uniformização do Direito Internacional Privado. No contexto do continente americano, há variadas legislações sobre a matéria desde o século XIX e, para o estudo das convenções especializadas hodiernamente, devem ser consideradas as codificações antecessoras, que buscaram fortalecer as relações entre os Estados americanos também no aspecto jurídico. Entretanto, não se pode desvincular o peso político e histórico das negociações e debates sobre o tema, pois foram tais aspectos que tornaram possível o desenvolvimento do Direito Internacional Privado americano.

A Uniformização do Direito Internacional Privado nas Américas atravessou duas etapas marcantes. A atual fase foi iniciada com a abertura das CIDIPs. Essas Conferências são

le, de Brasil, de Argentina, de Paraguay, de Haití, de República Dominicana, de Estados Unidos de América y de Cuba, Deseando que sus países respectivos estuvieran representados enla Sexta Conferencia Internaci onal Americana, enviaron a ella, debidamente autorizados para aprobarlasrecomendaciones, resoluciones, convenios y tratados que juzgarenútiles a losintereses de América, lossiguientesseñores Delegados [...] Hechoenlaciudad de La Habana, República de Cuba, eldíaveinte de febrero de mil novecientosveintiocho, encuatroejemplares escritos respectivamente encastellano, francés, inglés y portugués que se depositarán emla Oficina de laUniónPanamericana a fin de que envíe una copia certificada de todos a cada una de la Repúblicas signatarias.”(AYALA; et al, 1998, p. 713-716) Tradução Livre: Os Presidentes das Repúblicas do Peru, Uruguai, Panamá; do Equador, do México, de El Salvador, da Guatemala, da Nicarágua, da Bolívia, da Venezuela, da Colômbia, de Honduras, da Costa Rica, do Chile, do Brasil, da Argentina, do Paraguai, do Haiti, da República Dominicana, dos Estados Unidos da América e de Cuba, desejando que seus respectivos países estivessem representados na Sexta Conferência Internacional Americana, enviaram-lhe, devidamente autorizados a aprovar as recomendações, resoluções, acordos e tratados que considerem úteis aos interesses da América, os seguintes ilustres delegados [...] Feito na cidade de Havana, República de Cuba, aos vinte dias do mês de fevereiro de mil novecentos e vinte e oito, em quatro exemplares redigidos respectivamente em espanhol, francês, inglês e português que serão depositados na Secretaria da União Panamericana a fim de enviar uma cópia autenticada de tudo a cada uma das Repúblicas signatárias. 


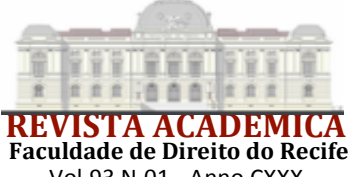

Vol.93 N.01 - Anno CXXX

caracterizadas pelo processo de codificação gradual, tendo preferência a discussão e elaboração de normas em matérias especializadas, centralizando os debates em matéria com maior aplicabilidade e eficácia. E, vê-se a tendência de participação expressiva dos Estados americanos, como, por exemplo, na CIDIP-I, com a adesão de dezenove Estados americanos, cooperando para a construção da padronização do Direito Internacional Privado em âmbito global.

Entretanto, em comparação às anteriores codificações, as CIDIPs constituem um formato recente, iniciado a partir da década de 1970, e que deve ser alvo de mais densas análises sobre as adesões e efetividade dos objetivos pretendidos. E o presente estudo teve pretensões de contribuir para a investigação do crescimento da estandardização do Direito Privado no contexto regional e mundial a partir de seus antecessores.

A primeira fase da Uniformização do Direito Americano foi marcada pelas centralizadoras codificações, com o Tratado de Lima de 1878, os Tratados de Montevidéu de 1888/1889 - e sua revisão em 1939/1940 - e o Código de Bustamante de 1928. Tais codificações foram essenciais para a estruturação dos temas de Direito Internacional Privado, mas não obtiveram aplicabilidade considerável, tendo em vista a sua ambição de uniformizar matéria de direito controversa e com diferentes abordagens, como o instituto da nacionalidade. Ademais, o surgimento de múltiplas legislações concorrentes também foi um empecilho para sua efetividade.

Entretanto, analisando-se os objetivos pretendidos na elaboração das codificações, resta demonstradoo interesse americano no fortalecimento da Uniformização do Direito Internacional Privado. A partir do Tratado de Lima de 1878, dos Tratados de Montevidéu de 1889 e 1940 e do Código de Bustamante de 1928, verificou-se o pioneirismo e vanguardismo do continente americano, colaborando para a ampliação do estudo do tema.

\section{REFERÊNCIAS}

ARGENTINA. Lei no 3192, de 6 de dezembro de 1894. Leyaprobatoria de los Tratados de Derecho Internacional de propiedadliteraria, marcas de fábrica, de Comercio, y patentes de invención. Buenos Aires, Argentina: Congreso de la Nación Argentina, [1894]. Disponível em: https://www.argentina.gob.ar/normativa/nacional/ley-3192-49053. Acesso em: 20 out. 2020.

AYALA, Elixeno; SCAVONE, Rosa MaríaGiagni de; RUIZ, Carmen Montanía de; SZARÁN, Roberto Úbeda (coord.). Compilación de Tratados de Derecho Internacional Privado suscritosenel sistema interamericano entre 1888 y 1994. Assunção, Paraguai: Corte Suprema de Justicia, Centro Internacional de EstudiosJudiciales, 1998.813 p. Disponível em: https://www.pj.gov.py/ebook/comp-trat-der-inter-priv.php. Acesso em: 19 out. 2020.

BARZA, Eugênia Cristina Nilsen Ribeiro. Integração Regional e Direito Internacional LatinoAmericano: um Estudo Segundo o Direito Internacional. Revista Jurídica da Seção Judiciária de Pernambuco, Pernambuco, n. 02, p. 111-129, 2009. Disponível em:

https://revista.jfpe.jus.br/index.php/RJSJPE/article/view/7/9. Acesso em: 12 mar. 2021.

BELANDRO, Ruben B. Santos. Vigencia de los tratados de Montevideo de 1889 y 1940 a la luz de las CIDIP I, II y III. Revista de informação legislativa, Brasília, v. 26, n. 103, p. 295-310, jul./set. 1989. Disponível em: https://www2.senado.leg.br/bdsf/item/id/181986. Acesso em: 27 out. 2020. 


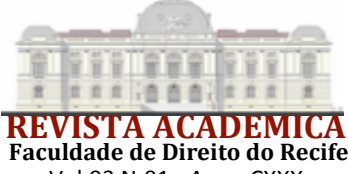

Faculdade de Direito do Recife

Vol.93 N.01 - Anno CXXX

BLOKKER, Paul; THORNHILL, Chris. Constututionalism between Nation States and Global Law. Cambridge University Press. Cambridge, p. 125-177, 2017. Disponível em:

https://www.research.manchester.ac.uk/portal/en/publications/constitutionalism-between-nationstates-and-global-law(3965f541-975f-4731-86aa-0bf1cb8cc522).html. Acesso em: 12 mar. 2021.

\section{BRASIL. Ministério das Relações Exteriores. Relatório da Repartição dos Negócios}

Estrangeiros. Rio de Janeiro, RJ: Ministério das Relações Exteriores, 1877. 464 p. Disponível em: http://www.funag.gov.br/chdd/index.php/relatorios-do-ministerio. Acesso em: 19 out. 2020.

DOLINGER, Jacob. Ordem pública mundial: ordem pública verdadeiramente internacional no Direito Internacional Privado. Revista de Informação Legislativa, Brasília, a. 23, n. 90, p. 205232, abr./jun. 1986. Disponível em: http://www2.senado.leg.br/bdsf/handle/id/496822. Acesso em: 19 out. 2020 .

GARTH, Bryant G. The Globalizationofthe Law. In: CALDEIRA, Gregory A.; KELEMEN, R. Daniel; WHITTINGTON, Keith E. The Oxford Handbookof Law andPolitics. Oxford:Oxford Handbooks, 2009. Disponível em:

https://www.oxfordhandbooks.com/view/10.1093/oxfordhb/9780199208425.001.0001/oxfordhb9780199208425-e-14. Acesso em: 12 mar. 2021.

GASPAR, Renata Alvares; JACOB, Mariana Romanello. Las Cláusulas de Integración bajo la óptica de la CIDIP: el papel de ese instrumento enlaconsecución de lacooperación judicial interamericana. Anuario Mexicano de Derecho Internacional, México, v. 24, p. 687-726, 2014. Disponível em: https://revistas.juridicas.unam.mx/index.php/derechointernacional/article/view/467. Acesso em: 19 out. 2020.

PARAGUAI. Lei n ${ }^{\circ} 266$ de 19 de julho de 1955. Por lacual se aprueban vários tratados y conveniosinternacionales. JustiaParaguay. Assunção: Câmara de Representantes da Nação Paraguaia, [1955]. Disponível: https://paraguay.justia.com/nacionales/leyes/ley-266-jul-191955/gdoc. Acesso em: 05 jan. 2021.

PARAGUAI. Lei n ${ }^{\circ} 584$ de 26 de maio de 1960. Por elcual se aprueba y ratifica el Tratado de Derecho Penal Internacionales, suscritoen Montevideo el 19 de marzo de 1940.

JustiaParaguay,Assunção: Câmara de Representantes da Nação Paraguaia, [1960]. Disponível: https://paraguay.justia.com/nacionales/leyes/ley-584-may-26-1960/gdoc/. Acesso em: 05 jan. 2021.

ORGANIZAÇÃO DOS ESTADOS AMERICANOS. Assembleia Geral. Sexta Conferência Especializada Interamericana sobre Direito Internacional Privado (CIDIP-VI). Ata Final. Washington, D.C.: CIDIP-VI, 2002.66 p. Disponível em:

https://www.oas.org/consejo/pr/CAJP/dir\%20internacional.asp. Acesso em: 20 out. 2020.

ORGANIZAÇÃO DOS ESTADOS AMERICANOS. Assembleia Geral. Sétima Conferência Especializada Interamericana sobre Direito Internacional Privado (CIDIP-VII). Ata Final. Washington, D.C.: CIDIP-VII, 2009. 8 p. Disponível em: https://www.oas.org/consejo/pr/CAJP/dir\%20internacional.asp. Acesso em: 20 out. 2020.

ORGANIZAÇÃO DOS ESTADOS AMERICANOS. Assembleia Geral. Oitava Conferência Especializada Interamericana sobre Direito Internacional Privado (CIDIP-VIII). Selectionoftopics for apossibleEighthInter-americanSpecializedConferenceon Private 
International Law. Washington, D.C.: CIDIP-VIII, 2011. 5 p. Disponível em: https://www.oas.org/consejo/pr/CAJP/dir\%20internacional.asp. Acesso em: 20 out. 2020.

ORGANIZAÇÃO DOS ESTADOS AMERICANOS. Centenariodel CJI. Washington, DC: OEA, [2020]. Disponível em: http://www.oas.org/es/sla/cji/centenario.asp. Acesso em: 19 out. 2020 .

ORGANIZAÇÃO DOS ESTADOS AMERICANOS. Nossa História. Washington, DC: OEA, [2020]. Disponível em: http://www.oas.org/pt/sobre/nossa_historia.asp. Acesso em: 19 out. 2020.

\section{ORGANIZAÇÃO DOS ESTADOS AMERICANOS. Tratado para EstablecerReglas}

Uniformes enMateria de Derecho Internacional Privado 1877. In: ARCHIVO diplomático delPerú. Congresos Americanos de Lima: Recopilación de Documentos precedida de Prólogo por Alberto Ulloa. t. 2. Disponível em:

https://www.oas.org/sap/peacefund/VirtualLibrary/virtualLibrary.html\#8. Acesso em: 03 nov. 2020 .

PARRA-ARANGUREN, Gonzalo. La primera etapa de los tratados sobre Derecho Internacional Privado en América (1826-1940). Revista de laFacultad de Ciencias Jurídicas y Políticas de laUniversidad Central de Venezuela, Caracas, n. 98, p. 60-128, 1996. Disponível em: http://www.ulpiano.org.ve/revistas/php/buscar.php?Opcion=detalle\&Expresion=N:8483\&Format $\mathrm{o}=\mathrm{a} \&$ base $=$ artic\&cipar=artic.par. Acesso em: 03 nov. 2020.

RECH, Carolina Magalhães. As Conferências Interamericanas de Direito Internacional Privado. In: SEMINÁRIO DE INICIAÇÃO CIENTÍFICA DA PU, 16., 2008, Rio de Janeiro. Relatórios Anuais [...]. Rio de Janeiro: Puc-Rio, 2008. Disponível em: http://www.pucrio.br/Pibic/relatorio resumo2008/. Acesso em: 19 out. 2020.

REZA, Germán A. de la. La dialécticadelfracaso: elCongreso americano de Lima (1847-1848) y su desenlace. Cuadernos Americanos, México, n. 134, p. 11-26, 2010. Disponível em: http://www.cialc.unam.mx/cuadamer/textos/ca134-11.pdf. Acesso em: 20 out. 2020.

RODAS, João Grandino; MONACO, Gustavo Ferraz de Campos. A Conferência da Haia de direito internacional privado: a participação do Brasil. Brasília, DF: Fundação Alexandre de Gusmão, 2007. 580 p. Disponível em: https://www.justica.gov.br/sua-protecao/cooperacaointernacional/subtracao-internacional/arquivos/. Acesso em: 9 out. 2020.

VILLELA, Ana Maria. A unificação do direito na América Latina: direito uniforme e direito internacional privado. Revista de Informação Legislativa, Brasília, ano 21, n. 83, p. 5-26, jul./set. 1984. Disponível em: http://www2.senado.leg.br/bdsf/handle/id/181517. Acesso em: 19 out. 2020.

VIZCARRA, Ana Elizabeth Villalta. El Derecho Internacional Privado enel Sistema Interamericano.In: SEMINÁRIO DA ASOCIACIÓN MEXICANA DE DERECHO A LA INFORMACIÓN A. C. (AMEDI), 2012. México, DF. Anais [...]. México, DF:[s. n.], set. 2012. p. 1-23. Disponível em: https://sociedip.files.wordpress.com/2013/12/el-derecho-internacionalprivado-en-el-sistema-interamericano-ana-elizabeth-villalta-viscarra.pdf. Acesso em: 12 mar. 2021. 